\title{
AUDIT ENERGI UNTUK EFISIENSI ENERGI PADA GEDUNG PT. SEJAHTERA INDOBALI TRADA
}

\author{
I Wayan Alit Sutresna ${ }^{1}$, Antonius Ibi Weking ${ }^{2}$, I Wayan Rinas ${ }^{3}$ \\ ${ }^{1,2,3}$ Program Studi Teknik Elektro Fakultas Teknik Universitas Udayana \\ Email:alit.sutresna@yahoo.com ${ }^{1}$, tony@ee.unud.ac.id $^{2}$, rinas@unud.ac.id $^{3}$
}

\begin{abstract}
ABSTRAK
PT. Sejahtera Indobali Trada adalah perusahaan pelayanan perawatan dan penjualan kendaraan mobil. Kepuasan konsumen dengan kualitas pelayanan terbaik sangat diutamakan oleh perusahaan ini. Pelayanan terbaik harus diikuti pula dengan penggunaan fasilitas secara efektif. Untuk itu, perlu dilakukan manajemen energi. Audit energi merupakan langkah awal dalam manajemen energi. Audit energi ini bertujuan untuk mengetahui penggunaan energi listrik dan persentase peluang penghematan. Audit energi meliputi pengumpulan data energi bangunan dengan data yang tersedia serta melakukan perhitungan Intensitan Konsumsi Energi (IKE) berdasarkan data yang telah dikumpulkan. Sebelumnya, PT. Sejahtera Indobali Trada belum pernah dilakukan audit energi. Metode penelitian ini dilakukan dengan cara menghitung dan membandingkan konsumsi energi listrik pada sistem pencahayaan dan pengkondisian udara antara sebelum dan sesudah audit energi. Hasil penelitian didapatkan penghematan sebesar $6,82 \%$ dengan selisih IKE antara pra audit dan pasca audit sebesar $0,59 \mathrm{kWh} / \mathrm{m}^{2} / \mathrm{bln}$.
\end{abstract}

Kata Kunci : Audit Energi, Pencahayaan, Pengkondisian Udara

\section{ABSTRACT}

PT. Sejahtera Indobali Trada is a car maintenance and sales service company. Excellent customer satisfaction is prioritized by this company. The best service must be done by using facilities effectively. For this reason, energy management is needed. Energy auditing is the first step in energy management. Energy audit to find out the use of electricity and opportunities. Energy audit includes the contents of energy data with available data and calculating Energy Consumption Intensity (IKE) based on the data collected. Previously, PT. Sejahtera Indobali Trada has never conducted an energy audit. This research method is done by calculating and comparing electrical energy in energy and energy systems. The results were obtained at $6.82 \%$ with the IKE difference between pre-audit and post-audit amounting to 0.59 $\mathrm{kWh} / \mathrm{m} 2$ / month.

\section{Keywords : Energy Audit, Lighting, Air Conditioning}

\section{PENDAHULUAN}

Kemajuan suatu perusahaan didukung oleh kinerja dari pegawai dan fasilitas yang memadai, salah satunya adalah PT. Sejahtera Indobali Trada. Perusahaan yang maju adalah perusahaan yang mampu mengandalkan fasilitasnya secara efektif dan efisien. Fasilitas umum pada perusahaan bisa berupa pencahayaan, pengkondisian udara dan sebagainya yang dapat mendukung kinerja perusahaan tersebut. PT. Sejahtera Indobali Trada sangat memperhatikan kualitas pelayanan terbaik, baik pada konsumen maupun karyawannya sendiri. Pemeriksaan kualitas peralatan perusahaan agar tetap sesuai dengan fungsinya sangat perlu dilakukan agar tidak terjadi pemborosan atau kerugian jangka panjang bagi perusahaan. Penerangan lampu dan pengkondisian udara adalah contoh fasilitas perusahaan yang menggunakan energi listrik. Pemanfaatan yang lebih baik pada kedua fasilitas tersebut, akan diikuti pula dengan penggunaan energi listrik yang lebih hemat. Usaha ini disebut dengan audit energi.

Audit energi ini bertujuan untuk mengetahui profil penggunaan energi listrik dan persentase penghematannya. Metode yang digunakan dalam audit ini dengan cara menghitung dan menganalisis pemanfaatan energi listrik di dalam sistem penerangan dan sistem pengkondisian udara serta merubah prosedur penggunaannya.

Persentase penghematan yang didapat sebesar $6,82 \%$ dari Intensitas Konsumsi 
Energi pra audit sebesar 8,65 (kWh/m²/bln) menjadi 8,06 (kWh/m²/bln) pasca audit.

Proses audit energi masih jarang dilakukan di Indonesia terutama pada gedung-gedung komersial seperti gedung perkantoran, universitas, rumah sakit, industri, dsb.[1]

Kenyataannya, PT. Sejahtera Indobali Trada belum pernah dilakukan audit energi. Maka dari itu, perlu dilakukan audit energi dengan tujuan untuk menge-tahui besarnya penggunaan energi listrik dan nilai IKE serta mengetahui persentase penghematan energi setelah dilakukan manajemen energi. Audit ini akan dititik beratkan pada sistem pencahayaan dan sistem pengkondisian udara.

\section{KAJIAN PUSTAKA}

Mencakup teori-teori penunjang yang dijadikan acuan yang meliputi manajemen energi, audit energi beserta intensitas konsumsi energi.

\subsection{Manajemen Energi}

Manajemen energi adalah program terpadu yang dirancang dengan sangat baik dan dilaksanakan dengan sistematik untuk pemanfaatan energi secara efektif dan efisien. Beberapa bagian program dari manajemen energi yaitu [2]:

1. Meningkatkan efisiensi energi dan mengurangi penggunaan energi.

2. Meningkatkan komunikasi yang baik pada persoalan energi.

3. Pengembangan dan perawatan dengan monitoring yang efektif, reporting, dan strategi manajemen untuk kebijakan penggunaan energi.

4. Mencari metode untuk meningkatkan pengembalian investasi energi melalui penelitian dan pengembangan (research and development).

5. Mengembangkan ketertarikan dan dedikasi terhadap program manajemen energi seluruh karyawan.

6. Mengurangi pengaruh dari pembatasan, atau setiap interrupt dalam supply energi.

\subsection{Audit Energi}

Audit energi merupakan surve teknis yang berguna dalam mengidentifikasi peluang penghematan dan mengetahui besarnya penggunaan energi suatu bangunan. Tujuan dari audit energi adalah untuk mengenali langkah-langkah penghematan serta mengetahui besar per- sentase peluang penghematannya. Hasil dari proses audit ini akan diketahui profil penggunaan energi pada sebuah bangunan sehingga dapat ditentukan sebuah rancangan strategis untuk mengendalikan penggunaan energi dalam bentuk laporan [3].

Prosedur audit energi pada bangunan gedung menurut SNI 03-6196:2000 [4]:

a. Audit Energi Awal

Audit energi awal adalah pengumpulan data awal dan memperkenalkan istilah seperti audit singkat dan survey awal. Audit energi awal dapat dilakukan pemilik/ pengelola gedung dengan data rekening pembayaran energi yang dikeluarkan. Audit energi awal meliputi pengumpulan data energi bangunan yang tersedia dan tidak memerlukan pengukuran.

b. Audit Energi Rinci

Audit energi rinci adalah tindak lanjut audit energi awal yang dilakukan jika nilai IKE tidak memenuhi target. Audit energi rinci juga perlu dilakukan untuk mengetahui peralatan apa saja yang menggunakan energi cukup besar. Kebalikan dari audit energi awal, audit energi rinci memerlukan pengukuran konsumsi energi.

c. Peluang Hemat Energi

Setelah melakukan audit energi awal dan audit energi rinci maka diperlukan analisa untuk mengetahui persentase peluang penghematan yang bisa dilakukan. Dari data yang dikumpulkan selanjutnya dilakukan perhitungan nilai Intensitas Konsumsi Energi (IKE). Jika hasil perhitungan ternyata sama atau kurang dari IKE target maka audit energi rinci dapat dihentikan.

d. Rekomendasi

Rekomendasi meliputi masalah:

1. Pengelolaan energi merupakan bagian program manajemen yang perlu diperbaiki, implementasi audit energi yang lebih baik dan cara meningkatkan kasadaran penghematan energi.

2. Pemanfaatan energi, termasuk langkah-langkah:

a. Peningkatan efisiensi penggunaan energi tanpa biaya seperti mengubah prosedur.

b. Perbaikan dengan investasi, baik dalam skala kecil maupun besar. 


\subsection{Intensitas Konsumsi Energi (IKE)}

Istilah Intensitas Konsumsi Energi (IKE) digunakan untuk menyatakan besarnya pemakaian energi dalam sebuah bangunan gedung yang sudah diterapkan di beberapa negara (ASEAN dan APEC), dinyatakan dalam satuan $\mathrm{kWh} / \mathrm{m}^{2} /$ tahun [5]. Nilai standar IKE untuk bangunan gedunggedung di Indonesia dapat dilihat pada Tabel 1.

Tabel 1. Standar IKE untuk bangunan gedung di Indonesia [5]

\begin{tabular}{|c|l|c|}
\hline No & \multicolumn{1}{|c|}{ Jenis Gedung } & $\begin{array}{c}\text { IKE }[\mathrm{kWh} / \mathrm{m} 2 / \\
\text { Tahun }\end{array}$ \\
\hline 1 & Perkantoran (Komersial) & 240 \\
\hline 2 & Pusat Perbelanjaan & 330 \\
\hline 3 & Hotel dan Apartemen & 300 \\
\hline 4 & Rumah Sakit & 380 \\
\hline
\end{tabular}

Nilai standar IKE untuk bangunan di Indonesia yang telah ditetapkan oleh Departemen Pendidikan Nasional Republik Indonesia pada tahun 2004 [5]. Ruangan yang menggunakan $A C$ dan tanpa $A C$ memiliki standar IKE yang dapat dilihat pada Tabel 2.

Tabel 2. Standar IKE untuk Ruangan AC dan tanpa

\begin{tabular}{|c|c|c|}
\hline Kriteria & $\begin{array}{l}\text { Ruangan AC } \\
\left(\mathrm{kWh} / \mathrm{m}^{2} / \mathrm{bln}\right)\end{array}$ & $\begin{array}{c}\text { Ruangan } \\
\text { Tanpa AC } \\
\text { (kWh/m²/bln) }\end{array}$ \\
\hline Sangat Efisien & $4,17-7,92$ & $0,84-1,67$ \\
\hline Efisien & $7,92-12,08$ & $1,67-2,5$ \\
\hline Cukup Efisien & $12,08-14,58$ & - \\
\hline Agak Boros & $14,58-19,17$ & - \\
\hline Boros & $19,17-23,75$ & $2,5-3,34$ \\
\hline Sangat Boros & $23,75-37,75$ & $3,34-4,17$ \\
\hline
\end{tabular}

Pembagian Intensitas Konsumsi Energi (IKE) perkantoran terbagi menjadi beberapa bagian yaitu [3]:

1. Energy Intensive

Bangunan gedung seperti ini termasuk dalam kelompok yang memiliki tingkat IKE elektrik sebesar $340 \mathrm{kWh} / \mathrm{m} 2 /$ tahun $\pm 5 \%$. Indikasi ini menunjukan konsumsi energi elektrik pada bangunan gedung tersebut adalah boros.

2. Base Case

IKE elektriknya berada pada angka 240 $\mathrm{kWh} / \mathrm{m} 2 /$ tahun $\pm 5 \%$. Hal ini menunjukan bahwa bangunan gedung tersebut tidak terkelola dengan baik tetapi tidak dikategorikan boros.
3. Energy Standard

IKE elektriknya berada pada nilai 180 $\mathrm{kWh} / \mathrm{m} 2 /$ tahun $\pm 5 \%$, nilai ini menunjukkan bahwa bangunan gedung tersebut telah dapat mengelola energi elektriknya dengan baik dan sudah melaksanakan program hemat energi.

4. Energy Efficiency

IKE elektriknya memiliki nilai sebesar $145 \mathrm{kWh} / \mathrm{m} 2 /$ tahun $\pm 5 \%$. Hal ini menunjukkan bahwa bangunan gedung ini telah mengelola energi elektriknya secara optimal sehingga menjadi hemat dan efisien.

\section{METODOLOGI PENELITIAN}

Metode yang digunakan dalam audit energi ini meliputi tahapan sebagai berikut:

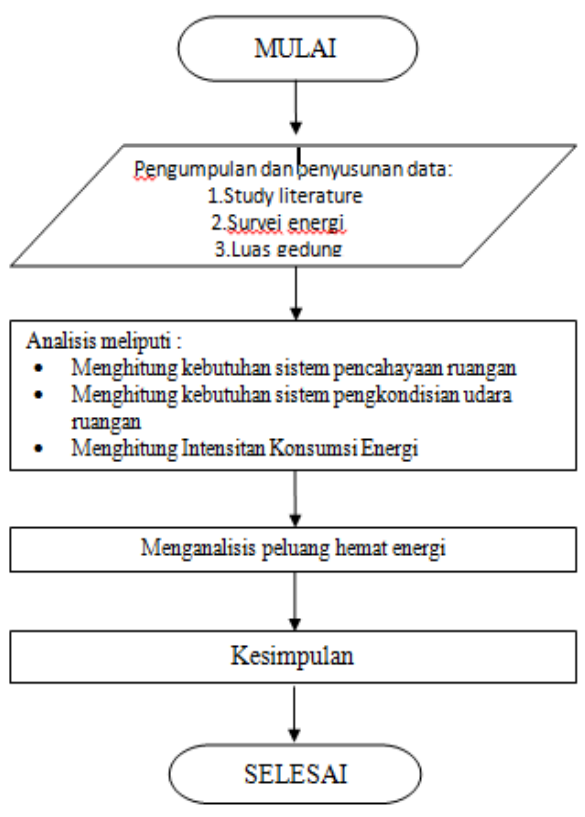

Gambar 1. Alur Analisis

\subsection{Data Dan Sumber Data}

Data yang digunakan dalam pelaksanaan audit energi ini diperoleh dari internet dan studi literatur buku-buku.

\subsection{Analisa Data}

Analisa dalam penelitian Tugas Akhir ini dilakukan dalam beberapa tahapan sebagai berikut:

1. Pengumpulan dan penyusunan data energi dengan melakukan survei energi listrik, menentukan luas gedung dan study literatur.

2. Melakukan perhitungan:

a) Menghitung kebutuhan sistem penerangan pada setiap ruangan 
b) Menghitung kebutuhan sistem pengkondisian udara ruangan

c) Menghitung Intensitas Konsumsi Energi

3. Menghitung efisiensi energi yang didapatkan setelah melakukan langkahlangkah analisa untuk efisiensi dengan membandingkan Intensitas Konsumsi Energi (IKE) sebelum dan sesudah audit yang dapat dilihat pada Persamaan (1)

$$
\gamma=\frac{I K E \text { pra audit }-I K E \text { pasca audit }}{\text { IKE pra audit }} \times 100 \% \text {... }
$$

\section{HASIL DAN PEMBAHASAN}

Membahas tentang hasil audit energi, rekomendasi peluang penghematan dan persentase penghematan.

\subsection{Pengukuran Intensitas Cahaya}

Intensitas penerangan (lux) adalah suatu matrik ukuran cahaya pada suatu permukaan yang setara dengan satu lumen per meter. Hasil pengukuran intensitas cahaya yang dilakukan pada ruanganruangan dapat dilihat pada Tabel 3.

Tabel 3. Hasil pengukuran intensitas cahaya
\begin{tabular}{|c|l|c|c|}
\hline No & \multicolumn{1}{|c|}{ Nama Ruangan } & $\begin{array}{c}\text { Luas } \\
\text { Ruangan } \\
\left(\mathrm{m}^{2}\right)\end{array}$ & $\begin{array}{c}\text { Hasil } \\
(\text { Iux })\end{array}$ \\
\hline 1 & R. Kapala Bengkel & 5,32 & 80 \\
\hline 2 & R. Admin & 7,84 & 205 \\
\hline 3 & R. Pendaftaran & 192 & 190 \\
\hline 4 & Toilet Service & 6,16 & 38 \\
\hline 5 & Ruang Metting & 36,21 & 320 \\
\hline 6 & Ruang Kasir & 15,12 & 200 \\
\hline 7 & R. Operator GA & 31,28 & 240 \\
\hline 8 & Ruang Tunggu & 85,8 & 82 \\
\hline 9 & Toilet R. Tunggu & 8,64 & 40 \\
\hline 10 & Area Bengkel & 1,348 & 200 \\
\hline 11 & Toilet Area Bengkel & 15,6 & 105 \\
\hline 12 & Ruang Mekanik & 14,8 & 93 \\
\hline 13 & Ruang Spare Part & 22,4 & 143 \\
\hline 14 & Gudang Spare Part & 48,0 & 127 \\
\hline 15 & Gudang Claim & 6,75 & 137 \\
\hline 16 & Ruang Alat & 8,1 & 144 \\
\hline 17 & Ruang Over Houl & 10,8 & 200 \\
\hline 18 & Ruang Oli & 5,4 & 72 \\
\hline 19 & Ruang Ganset & 10,8 & 68 \\
\hline 20 & Ruang Kompresor & 5,4 & 73 \\
\hline & & & \\
\hline
\end{tabular}

Berdasarkan pengukuran IKE untuk sistem penerangan secara langsung pada ruang kerja PT. Sejahtera Indabali Trada di- dapatkan hasil yang berbeda-beda dan IKE penerangan yang belum memenuhi standar untuk ruang kerja yaitu sebesar 300 lux.

\subsection{Pengukuran Temperatur}

Temperatur adalah ukuran panas atau dingin suatu ruangan yang kita gunakan. Alat yang digunakan untuk mengukur temperatur disebut termometer. Hasil pengukuran temperatur pada ruangan yang menggunakan sistem pengkondisian udara dapat dilihat pada Tabel 4 .

Tabel 4. Hasil pengukuran temperatur
\begin{tabular}{|c|l|c|c|}
\hline No & Nama Ruangan & Luas $\left(\mathrm{m}^{2}\right)$ & Hasil \\
\hline 1 & R. Admin & 7,84 & $24,6^{\circ} \mathrm{C}$ \\
\hline 2 & R. Pendaftaran & 192 & $24,5^{\circ} \mathrm{C}$ \\
\hline 3 & Ruang Rapat & 36,21 & $27,1^{\circ} \mathrm{C}$ \\
\hline 4 & Ruang Kasir & 15,12 & $26,7^{\circ} \mathrm{C}$ \\
\hline 5 & R. Operator GA & 31,28 & $27,5^{\circ} \mathrm{C}$ \\
\hline 6 & Ruang Tunggu & 85,8 & $26,6^{\circ} \mathrm{C}$ \\
\hline 7 & Ruang Spare Part & 22,4 & $26,9^{\circ} \mathrm{C}$ \\
\hline
\end{tabular}

\subsection{Standar Kebutuhan Sistem Pencahayaan}

Penerangan yang baik dan merata didapatkan dengan mempertimbangkan iluminasi, sudut penyinaran lampu, jenis dan jarak penempatan lampu sesuai dengan kegiatan di ruangan tersebut. Bila perhitungan ini diterapkan, maka akan dihasilkan kondisi ruang kerja dengan tingkat pencahayaan yang sesuai dan nyaman. Hal tersebut diikuti pula dengan bertambahnya tingkat konsumsi energi yang cukup besar. Perbandingan IKE sistem penerangan antara kondisi existing dengan standar yang ditetapkan dapat dilihat pada Tabel 5.

\subsection{Standar Kebutuhan Sistem Pengkondisian Udara}

Penggunaan energi listrik pada sistem pengkondisian udara lebih besar dibandingkan sistem penerangan. Maka dari itu, disarankan penggunaan peralatan AC harus sesuai dengan kebutuhan masing-masing ruangan. Bila perhitungan ini diterapkan, maka dihasilkan kondisi ruang kerja yang nyaman serta konsumsi energi yang lebih efisien, namun dengan nilai investasi yang cukup besar. Perbandingan IKE sistem pengkondisian udara antara kondisi existing dengan standar yang ditetapkan dapat dilihat pada Tabel 6 . 
Tabel 5. Perbandingan IKE untuk sistem penerangan antara kondisi existing dengan perhitungan standar

\begin{tabular}{|c|c|c|c|c|c|c|}
\hline \multirow[b]{2}{*}{ No } & \multirow[b]{2}{*}{ Nama Ruangan } & \multicolumn{2}{|c|}{ Existing } & \multicolumn{2}{|c|}{ Standar } & \multirow[b]{2}{*}{ Selisih (kWh) } \\
\hline & & $\begin{array}{l}\text { Jumlah } \\
\text { Lampu }\end{array}$ & $\begin{array}{l}\text { Energi } \\
(\mathrm{kWh})\end{array}$ & $\begin{array}{l}\text { Jumlah } \\
\text { Lampu }\end{array}$ & $\begin{array}{l}\text { Energi } \\
(\mathrm{kWh})\end{array}$ & \\
\hline 1 & Ruang Kapala Bengkel & 1 & 0.396 & 1 & 0.396 & 0 \\
\hline 2 & Ruang Admin & 2 & 0.792 & 3 & 1.188 & -0.396 \\
\hline 3 & Ruang Pendaftaran & 19 & 8.208 & 46 & 39.74 & -31.536 \\
\hline 4 & Toilet Service & 2 & 0.864 & 2 & 0.864 & 0 \\
\hline 5 & Ruang Metting & 6 & 0.216 & 10 & 3.96 & -0.744 \\
\hline 6 & Ruang Kasir & 4 & 1.584 & 5 & 1.98 & -0.396 \\
\hline 7 & Ruang Operator GA & 4 & 1.584 & 9 & 3.564 & -1.98 \\
\hline 8 & Ruang Tunggu & 27 & 11.66 & 15 & 5.94 & 5.724 \\
\hline 9 & Toilet R. Tunggu & 3 & 1.296 & 3 & 1.296 & 0 \\
\hline 10 & Area Bengkel & 28 & 11.09 & 211 & 83.56 & -72.468 \\
\hline 11 & Toilet Bengkel & 1 & 0.864 & 1 & 0.864 & 0 \\
\hline 12 & Ruang Mekanik & 2 & 0.792 & 1 & 0.864 & -0.072 \\
\hline 13 & Ruang Spare Part & 4 & 1.584 & 3 & 1.188 & 0.396 \\
\hline 14 & Gudang Spare Part & 5 & 1.98 & 5 & 1.98 & 0 \\
\hline 15 & Gudang Claim & 2 & 0.792 & 1 & 0.396 & 0.396 \\
\hline 16 & Ruang Alat & 2 & 0.792 & 1 & 0.396 & 0.396 \\
\hline 17 & Ruang Over Houl & 2 & 0.792 & 1 & 0.396 & 0.396 \\
\hline 18 & Ruang Oli & 1 & 0.396 & 1 & 0.396 & 0 \\
\hline 19 & Ruang Ganset & 1 & 0.396 & 1 & 0.396 & 0 \\
\hline 20 & Ruang Kompresor & 1 & 0.396 & 1 & 0.396 & 0 \\
\hline 1 & Ruang Kapala Bengkel & 1 & 0.396 & 1 & 0.396 & 0 \\
\hline
\end{tabular}

Tabel 6. Perbandingan IKE untuk sistem pengkondisian udara antara kondisi existing dengan perhitungan standar

\begin{tabular}{|c|c|c|c|c|c|}
\hline \multirow{2}{*}{ No } & \multirow{2}{*}{ Nama Ruangan } & \multicolumn{2}{|c|}{ Existing } & \multirow{2}{*}{$\begin{array}{c}\text { Standar } \\
\text { Energi (kWh) }\end{array}$} & \multirow{2}{*}{ Selisih (kWh) } \\
\hline & & Jumlah & Energi (kWh) & & \\
\hline 1 & Ruang Admin & 1 & 12.9 & 4.1 & 8.8 \\
\hline 2 & Ruang Pendaftaran & 2 & 77.11 & 49.24 & 27.87 \\
\hline 3 & Ruang Rapat & 1 & 1.3 & 0.746 & 0.554 \\
\hline 4 & Ruang Kasir & 1 & 8.22 & 4.1 & 4.12 \\
\hline 5 & Ruang Operator & 1 & 14.96 & 8.21 & 6.75 \\
\hline \multirow{2}{*}{6} & \multirow{2}{*}{ Ruang Tunggu } & 1 & 37.99 & \multirow{2}{*}{32.82} & \multirow{2}{*}{17.32} \\
\hline & & 1 & 12.15 & & \\
\hline 7 & Ruang Spare Part & 1 & 12.52 & 12.31 & 0.21 \\
\hline
\end{tabular}

\subsection{Rekomendasi Sistem \\ Pencahayaan Menggunakan LED}

Peluang penghematan yang dapat direkomendasikan pada sistem penerangan yaitu dengan cara mengganti lampu TL/SL dengan lampu LED. Selain menghasilkan lux yang tinggi, masa pemakaian lampu
LED juga lebih awet dibandingkan lampu TL/SL. Maka dari itu, investasi yang mahal akan sebanding dengan masa pakai lampu. Penghematan yang didapat dari sistem pencahayaan dapat dilihat pada Tabel 7.

Tabel 7. Persentase penghematan sistem pencahayaan antara pra audit dan pasca audit setelah menggunakan LED

\begin{tabular}{|c|c|c|c|c|c|c|c|c|}
\hline \multirow[b]{2}{*}{ No } & \multirow[b]{2}{*}{ Ruangan } & \multirow[b]{2}{*}{$\begin{array}{l}\text { Jumlah } \\
\text { Lampu }\end{array}$} & \multicolumn{2}{|c|}{ Pra Audit } & \multicolumn{2}{|c|}{ Pasca Audit } & \multirow[b]{2}{*}{$\begin{array}{l}\text { Penghematan } \\
\text { (kWh) }\end{array}$} & \multirow[b]{2}{*}{$\begin{array}{l}\text { Persentase } \\
\text { Penghematan } \\
\text { (\%) }\end{array}$} \\
\hline & & & $\begin{array}{l}\text { Daya } \\
\text { Lampu } \\
\text { (Watt) }\end{array}$ & kWh/hari & $\begin{array}{l}\text { Daya } \\
\text { Lampu } \\
\text { (Watt) }\end{array}$ & kWh/hari & & \\
\hline 1 & R. Kapala Bengkel & 1 & 36 & 0.40 & 23 & 0.25 & 0.14 & 36.11 \\
\hline 2 & R. Admin & 2 & 36 & 0.79 & 23 & 0.51 & 0.29 & 36.11 \\
\hline 3 & R. Pendaftaran & 19 & 36 & 7524.00 & 23 & 4807.00 & 2717.00 & 36.11 \\
\hline
\end{tabular}


... lanjutan Tabel 7. Perbandingan IKE untuk sistem penerangan

\begin{tabular}{|c|c|c|c|c|c|c|c|c|}
\hline \multirow[b]{2}{*}{ No } & \multirow[b]{2}{*}{ Ruangan } & \multirow[b]{2}{*}{$\begin{array}{l}\text { Jumlah } \\
\text { Lampu }\end{array}$} & \multicolumn{2}{|c|}{ Pra Audit } & \multicolumn{2}{|c|}{ Pasca Audit } & \multirow[b]{2}{*}{$\begin{array}{l}\text { Penghematan } \\
\text { (kWh) }\end{array}$} & \multirow{2}{*}{$\begin{array}{l}\text { Persentase } \\
\text { Penghematan } \\
\text { (\%) }\end{array}$} \\
\hline & & & $\begin{array}{l}\text { Daya } \\
\text { Lampu } \\
\text { (Watt) }\end{array}$ & kWh/hari & $\begin{array}{l}\text { Daya } \\
\text { Lampu } \\
\text { (Watt) }\end{array}$ & kWh/hari & & \\
\hline 4 & Toilet Service & 2 & 36 & 0.86 & 23 & 0.51 & 0.36 & 41.44 \\
\hline 5 & R. Metting & 6 & 36 & 0.22 & 23 & 0.14 & 0.08 & 36.11 \\
\hline 6 & Ruang Kasir & 4 & 36 & 1584.00 & 23 & 1012.00 & 572.00 & 36.11 \\
\hline 7 & R. Operator GA & 4 & 36 & 1584.00 & 23 & 1012.00 & 572.00 & 36.11 \\
\hline 8 & R. Tunggu & 27 & 18 & 5346.00 & 13 & 3861.00 & 1485.00 & 27.78 \\
\hline 9 & Toilet R. Tunggu & 3 & 18 & 1296.00 & 13 & 0.43 & 1295.57 & 99.97 \\
\hline 10 & Area Bengkel & 28 & 36 & $\begin{array}{c}11088.0 \\
0\end{array}$ & 23 & 7084.00 & 4004.00 & 36.11 \\
\hline 11 & Toilet Bengkel & 1 & 36 & 0.86 & 23 & 0.25 & 0.61 & 70.72 \\
\hline 12 & Ruang Mekanik & 2 & 36 & 0.79 & 23 & 0.51 & 0.29 & 36.11 \\
\hline 13 & R. Spare Part & 4 & 36 & 1584.00 & 23 & 1012.00 & 572.00 & 36.11 \\
\hline 14 & $\begin{array}{l}\text { Gudang Spare } \\
\text { Part }\end{array}$ & 5 & 36 & 1980.00 & 23 & 1265.00 & 715.00 & 36.11 \\
\hline 15 & Gudang Claim & 2 & 36 & 0.79 & 23 & 0.51 & 0.29 & 36.11 \\
\hline 16 & Ruang Alat & 2 & 36 & 0.79 & 23 & 0.51 & 0.29 & 36.11 \\
\hline 17 & R. Over Houl & 2 & 36 & 0.79 & 23 & 0.51 & 0.29 & 36.11 \\
\hline 18 & R. Oli & 1 & 36 & 0.40 & 23 & 0.25 & 0.14 & 36.11 \\
\hline 19 & R. Ganset & 1 & 36 & 0.40 & 23 & 0.25 & 0.14 & 36.11 \\
\hline 20 & R. Kompresor & 1 & 36 & 0.40 & 23 & 0.25 & 0.14 & 36.11 \\
\hline & TOTAL & & & 41.13 & & 24.92 & 16.21 & 39.41 \\
\hline
\end{tabular}

\subsection{Rekomendasi Sistem}

\section{Pengkondisian Udara}

Peluang penghematan yang direkomendasikan pada sistem pengkondisian udara dengan cara mengatur jam oprasional yaitu wajib mematikan AC 1 jam sebelum kegiatan kantor berakhir dan mematikan AC selama ruang kerja kosong atau tidak digunakan. Bila dapat dimatikan selama 1 jam, maka penggunaan energi listrik juga dapat di hemat. Besar penghematan yang dilakukan dapat dilihat pada Tabel 8.

Tabel 8. Persentase penghematan sistem pengkondisian udara

\begin{tabular}{|c|c|c|c|c|c|c|}
\hline \multirow{2}{*}{ No } & \multirow{2}{*}{ Nama Ruangan } & \multirow{2}{*}{ Jenis AC } & \multicolumn{2}{|c|}{ Konsumsi Energi (kWh) } & \multirow{2}{*}{$\begin{array}{l}\text { Penghematan } \\
\text { (kWh) }\end{array}$} & \multirow{2}{*}{$\begin{array}{c}\text { Persentase } \\
\text { Penghematan } \\
(\%)\end{array}$} \\
\hline & & & Pra Audit & Pasca Audit & & \\
\hline 1 & Ruang Admin & AC 2 PK & 12.90 & 11.61 & 1.29 & 10.00 \\
\hline 2 & Ruang Pendaftaran & AC 5 PK & 77.11 & 69.40 & 7.71 & 10.00 \\
\hline 3 & Ruang Rapat & $\mathrm{AC} 2 \mathrm{PK}$ & 1.30 & 1.30 & 0.00 & 0.00 \\
\hline 4 & Ruang Kasir & AC 1PK & 8.22 & 7.40 & 0.82 & 9.98 \\
\hline 5 & Ruang Operator GA & AC 2 PK & 14.96 & 13.46 & 1.50 & 10.03 \\
\hline \multirow{2}{*}{6} & \multirow{2}{*}{ Ruang Tunggu } & AC 5 PK & 37.99 & 34.19 & 3.80 & 10.00 \\
\hline & & AC 2 PK & 12.15 & 10.93 & 1.22 & 10.04 \\
\hline \multirow[t]{2}{*}{7} & Ruang Spare Part & $\mathrm{AC} 2 \mathrm{PK}$ & 12.52 & 11.27 & 1.25 & 9.98 \\
\hline & TOTAL & & 177.15 & 159.56 & 17.59 & 9.93 \\
\hline
\end{tabular}

Persentase penghematan dapat dilihat dalam perhitungan di bawah ini:

\section{IKE pra audit}

$=(k W h($ sistem pencahayaan $+\mathrm{AC}+$ peralatan $) \times 30) / \mathrm{m}^{2}$

$=((41,13+177,15+276,73) \mathrm{kWh} \times 30) / 1716 \mathrm{~m}^{2}$

$=14850,3 \mathrm{kWh} / 1716 \mathrm{~m}^{2}$

$=8,65 \mathrm{kWh} / \mathrm{m}^{2} /$ bulan

\section{IKE pasca audit}

$=(\mathrm{kWh}($ sistem pencahayaan $+\mathrm{AC}+$ peralatan $) \times 30) / \mathrm{m}^{2}$

$=((24,92+159,56+276,73) k W h \times 30) / 1716 m^{2}$

$=13836,3 \mathrm{kWh} / 1716 \mathrm{~m}^{2}$

$=8,06 \mathrm{kWh} / \mathrm{m}^{2} /$ bulan 
Jadi, nilai penghematan yang diper-oleh dapat dinyatakan dalam bentuk persen dengan menggunakan Persamaan (1) sehingga didapatkan persentase penghematan sebesar $6,82 \%$.

\section{SIMPULAN}

Simpulan yang dapat diperoleh dari hasil pengujian dan analisa ini adalah:

1. Besarnya konsumsi energi di gedung PT.Sejahtera Indobali Trada kondisi Existing pada sistem pencahayaan sebesar 41,13 kWh/m²/bln, sistem pengkondisian udara sebesar 177,15 $\mathrm{kWh} / \mathrm{m}^{2} / \mathrm{bln}$, dan untuk peralatan lain sebesar 276,73 $\mathrm{kWh} / \mathrm{m}^{2} / \mathrm{bln}$. Jadi pemakaian energi listrik (IKE) pada gedung PT. Sejahtera Indobali Trada adalah sebesar $8,65 \mathrm{kWh} / \mathrm{m}^{2} / \mathrm{bln}$.

2. Pemakaian energi listrik di gedung PT. Sejahtera Indobali Trada sudah termasuk dalam katagori pemakaian energi yang efisien, yaitu memiliki besar pemakaian antara $7,92 \mathrm{kWh} / \mathrm{m}^{2} / \mathrm{bln}$ sampai $12,08 \mathrm{kWh} / \mathrm{m}^{2} / \mathrm{bln}$.

3. Setelah melakukan audit energi pada gedung service PT. Sejahtera Indobali Trada dengan cara mengganti lampu TL dan SL menggunakan lampu LED dan mewajibkan pemakaian ruangan agar mematikan AC bila ruangan tidak dipergunakan dan mengatur jam operasional yaitu mematikan AC 1 jam sebelum jam kegiatan kantor berakhir, menghasilkan penghematan sebesar $6,82 \%$ dari pemakaian energi listrik (IKE) pra audit sebesar 8,65 $\left(\mathrm{kWh} / \mathrm{m}^{2} / \mathrm{bln}\right)$ menjadi $8,06\left(\mathrm{kWh} / \mathrm{m}^{2} / \mathrm{bln}\right)$ pasca audit. Hasil dari penghematan pemakaian energi listrik pada gedung PT. Sejahtera Indobali Trada menjadi lebih efisien.

\section{DAFTAR PUSTAKA}

[1] B. S. Nasional, "SNI 03-6196-2000, Prosedur Audit Energi Pada Bangunan Gedung," Jkt. BSN, 2000.

[2] B. L. Capehart, W. C. Turner, and W. J. Kennedy, Guide to energy management. The Fairmont Press, Inc., 2003.

[3] I. P. G. W. Setyawan, R. S. Hartati, and In. S. Kumara, "MANAJEMEN ENERGI DI RUMAH SAKIT SURYA HUSADHA DENPASAR."

[4] S. N. Indonesia, Prosedur audit energi pada bangunan gedung. Badan Standardisasi Nasional, 2000.
[5] S. Suhendar, "Audit Sistem Pencahayaan dan Sistem Pendingin Ruangan di Gedung Rumah Sakit Umum Daerah (RSUD) Cilegon," Setrum Sist. Kendali-Tenaga-Elektron.Telekomun.-Komput., vol. 2, no. 2, pp. 78-84, 2016. 